\title{
Respiratory symptoms in arable farmworkers: role of storage mites
}

\author{
A D BLAINEY, M D TOPPING, S OLLIER, R J DAVIES \\ From the Department of Respiratory Medicine, St Bartholomew's Hospital, and the Occupational Medicine and \\ Hygiene Laboratories, Health and Safety Executive, London
}

\begin{abstract}
Storage mites (acarid mites) are related to the house dust mite but are usually found in agricultural environments. They have been shown to cause allergic symptoms in Scottish farmworkers exposed to stored hay, but whether farmworkers who grow and store grain are also at risk is unknown. One hundred and one farmworkers on 22 Essex farms with grain storage facilities ( $88 \%$ of the available workforce) participated in a survey of respiratory symptoms, with skin tests and determination of serum levels of IgE specific for mite species, including storage mites. Of the 101 workers, 21 reported attacks of cough, wheeze, or breathlessness after exposure to stored grain and 15 reported nasal symptoms after grain exposure. Storage mite specific IgE was found in $59 \%$ of farmworkers with work related respiratory symptoms, in $60 \%$ with work related nasal symptoms, and in only $9 \%$ of symptomless farmworkers. Work related respiratory and nasal symptoms were also significantly associated with atopy, and with positive skin test responses and serum IgE specific for Dermatophagoides pteronyssinus. Storage mites were found in grain samples from 16 farms in which grain was sampled, whereas $D$ pteronyssinus was not found in any. The close association between serum storage mite specific IgE and occupational respiratory symptoms suggests that storage mites may be responsible for respiratory symptoms in these Essex farmworkers exposed to grain.
\end{abstract}

\section{Introduction}

Occupational exposure to grain dust has long been known to produce respiratory symptoms. Several components of grain dust have been implicated as the cause of these symptoms, including insect contaminants such as the grain weevil (Sitophilus granarius), ${ }^{1}$ mould spores contaminating harvested grain, ${ }^{2}$ and allergens from grain itself. ${ }^{3}$ More recently, storage mites have been proposed as a cause of respiratory symptoms in Scottish and European farmworkers exposed to stored hay. ${ }^{45}$

Little is known about the factors associated with respiratory symptoms in farmworkers exposed to stored grain. In North America, grainstore workers who develop respiratory symptoms do not have positive skin test responses to storage mites..$^{6-8}$ In Britain there have been no systematic studies of the relation between storage mites and respiratory symptoms in individuals who are occupationally exposed to stored grain.

Address for reprint requests: Dr $\mathbf{R} J$ Davies, Department of Respiratory Medicine, St Bartholomew's Hospital, London ECIA 7BE.

Accepted 16 June 1988

\section{Methods}

\section{FARMS AND WORKERS}

Twenty six farms in Essex with bulk grain storage facilities were contacted through the Employment Medical Advisory Service in Essex. Twenty two farms agreed to participate in the survey. The farms were visited by the interviewer and all employees working on the farm were invited to attend for interview. One hundred and fifteen farmworkers were available for interview, and $101(88 \%)$ agreed to participate. Of the 14 subjects who refused, eight said they had no occupational exposure to grain, two were away at the time of the survey, and four gave no reason. All subjects who agreed to participate reported current or recent grain exposure within the last year. There was no further information concerning the farms that refused to participate.

The workforce employed on each farm ranged from three to 11. All farms had grain storage facilities, which ranged from sheds capable of storing several hundred tonnes of grain to a few circular bins storing about 40-50 tonnes each. Some farms had facilities for drying grain.

Individual farmworkers' exposure to grain was very 
variable. Grain was usually harvested between early June and late August and left in store until it was taken to the market, which could be at any time over the next 10 months. Maximal grain exposure occurred when grain was being loaded from the store into lorries, usually with a mechanical hopper, or when it was being passed through a dryer. Only eight farms provided respiratory protection; some farmworkers wore simple face masks when dust concentrations were perceived as being high, and two farms issued Airstream helmets to their workers. Only seven workers used respiratory protection regularly.

Informed, written consent was obtained from all participating subjects.

\section{QUESTIONNAIRE}

A questionnaire designed for use with a microcomputer was administered verbally to all subjects on site at the farms. The results were recorded by one interviewer and transferred to storage disc. The questionnaire consisted of 122 questions relating to attacks of coughing, wheeze, or breathlessness; attacks of sneezing, nasal blockage, or rhinorrhoea; and the relation of these symptoms to potential precipitating factors, such as occupational exposure, exposure to domestic dust, and grass pollen. An occupational history, including details of exposure to grain dust, was also recorded. Subjects were regarded as having current respiratory symptoms if they reported more than one attack of wheezing, cough, or breathlessness within the last year, and current nasal symptoms if they reported more than one attack of rhinorrhoea, nasal blockage, or sneezing within the last year. Symptoms were considered to be occupationally related if they deteriorated at work and improved away from work, at weekends, and during holidays.

The reproducibility of the questionnaire responses has been assessed by repeat administration to 75 subjects. Concordance for answers to individual questions (the percentage of answers in agreement as a proportion of the number of answers) ranged from $69 \%$ to $84 \%$; the overall prevalence of respiratory symptoms was identical on the two occasions. ${ }^{9}$

\section{SKINPRICK TESTS}

\section{Domestic inhalant allergens}

Skinprick tests were performed by the method described by Pepys. ${ }^{10}$ Commercial extracts of Dermatophagoides pteronyssinus, grass pollen, Aspergillus fumigatus, cat fur, dog hair, and a negative control (Bencard, Brentford, Middlesex) were used for skin testing. Skinprick test weals were recorded at 12 minutes by tracing around the weal in ink and transferring this tracing to graph paper. The skin prick test weal area (in $\mathrm{mm}^{2}$ ) and the maximum diameter in $\mathrm{mm}$ were read directly from this.
Skinprick test responses were considered positive they were more than $2 \mathrm{~mm}$ greater in diameter than the negative control; subjects were regarded as atopic i悉 they had one or more positive skinprick test response to the above allergens.

\section{Storage mites}

Five species of storage mite were used in this study $\overrightarrow{\vec{\omega}}$ Glycyphagus destructor, Glycyphagus domesticus Acarus siro, Acarus farris, and Tyrophagus putrescentiae.

One per cent extracts were prepared in glycery saline $(50 \%$ aqueous glycerol, $6 \% \mathrm{NaCl}, 0 \cdot 5 \%$ pheno by tumble mixing $1 \mathrm{~g}$ of mites with $100 \mathrm{ml}$ glycery saline for 48 hours at $4^{\circ} \mathrm{C}$. This mixture was then centrifuged, and the supernatant passed through $\overrightarrow{\vec{b}}$ $0.22 \mu \mathrm{m}$ millipore filter. Extracts were stored at $4^{\circ} \Phi$ and used within three weeks of preparation. A extracts were coded and administered double blind. 3

TOTAL AND SPECIFIC IgE

Blood was taken from 89 subjects; 12 refused vene puncture. Serum was not available for four subjects, si there were 85 samples for measurement of total an specific IgE.

Total IgE was measured with a Phadebas PRIST ki (Pharmacia, Uppsala, Sweden).

Extracts for measurement of mite specific IgE wer尺

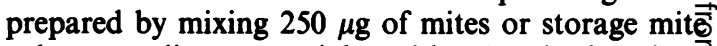
culture medium overnight with $10 \mathrm{ml}$ phosphate buffered saline (PBS) at room temperature. Extract were centrifuged at $48000 \mathrm{~g}$ for 30 minutes; the. supernatant was dialysed against 1 litre of PBS over night at $4^{\circ} \mathrm{C}$ and then stored at $-20^{\circ} \mathrm{C}$. For pteronyssinus specific IgE a commercial extract of $B$ pteronyssinus $(1 \cdot 2 \% \mathrm{w} / \mathrm{v}$; Bencard, Brentford) was used.

Cyanogen bromide was used to activate paper disco according to the method of Ceska, " with $5 \mathrm{ml}$ of mite extract $/ 600 \mathrm{mg}$ of activated disc. Allergen specific IgE was determined by incubating $200 \mu \mathrm{l}$ of $1: 4$ dilutio of test serum with allergen coated discs for 18 hours at. room temperature. After washing, bound $\mathrm{IgE}$ wał detected by further overnight incubation at room temperature with $50 \mu \mathrm{l}$ of anti-human IgE labelle with iodine-125 (Pharmacia, Uppsala, Sweden). Aftef removal of unbound ${ }^{125} I$, the ${ }^{125} I$ bound to the discs was measured with a LKB rackgamma II counter. AT assays were performed in duplicate and the result expressed as mean percentage counts of ${ }^{125} \mathrm{I}$ bound to the disc.

Human fetal cord serum was used as a negative control and was included in each assay run and wit each allergen disc type. The mean (SD) percentage binding for cord serum was $0.35 \%(0 \cdot 12 \%)(n=63)$ 
Percentage binding greater than the mean percentage binding to cord serum +2.5 times the standard deviation was taken to indicate the presence of specific IgE. In this study serum samples were tested against a mixed storage mite extract prepared by mixing $1 \mathrm{ml}$ of each of the five species of storage mite with $600 \mathrm{mg}$ of activated discs.

\section{MITE CONTENT OF STORED GRAIN}

Analyses of mite content of stored grain were undertaken by members of the Pest Infestation Control Laboratory of the Ministry of Agriculture, Cambridge. Samples of grain were taken from 16 of the 22 farms participating in the survey. The moisture content of the stored grain was measured, and mite species were identified visually.

\section{ANALYSIS}

Comparisons between proportions have been made by means of the $\chi^{2}$ test or Fisher's exact test where appropriate, and correlations assessed by ranking or linear methods, depending on the distribution of the variables. ${ }^{12} \mathrm{~A} p$ value of less than 0.05 was regarded as significant.

\section{Results}

\section{SUBJECTS}

One hundred farmworkers interviewed were male and one was female. Ages ranged from 17 to 69 with a mean of 42 years. The duration of farm employment ranged from six months to 50 (mean 23) years. Almost all the farmworkers interviewed had spent all of their working lives in agriculture, though not necessarily on the same farm, and many had helped with seasonal work in childhood before starting regular employment. None reported significant occupational exposure to other known respiratory hazards.

\section{QUESTIONNAIRES}

Forty seven subjects reported attacks of cough, wheeze, or breathlessness within the last year of whom 39 had attacks of coughing, 33 attacks of wheezing, and 21 attacks of breathlessness. In 21 of the 47 subjects one or more of these symptoms were related to grain dust exposure, in that they developed after exposure to grain dust and improved when the person was away from grain. No subject reported symptoms due to any agent other than grain dust. Grain dust related symptoms are therefore referred to as work related respiratory symptoms or work related nasal symptoms (table 1). Symptoms attributed to stored grain were likely to occur at any time of year, whenever the subjects were exposed to stored grain. Only one of the 21 subjects said that his symptoms were worst during the harvest.

Nasal symptoms were reported by 58 subjects, but only 15 reported that these were work related. In all, 24 subjects had work related symptoms, of whom nine had respiratory symptoms alone, three had nasal symptoms alone, and 11 had both respiratory and nasal symptoms.

One subject reported a history of previous farmer's lung. Forty subjects were current cigarette, cigar, or pipe smokers, 19 subjects had not smoked for more than one year, and 42 were lifetime non-smokers.

\section{SKINPRICK TESTS}

Thirty nine subjects were atopic and 60 non-atopic, and two had equivalent skin test responses to allergen and the negative control. Of the 39 atopic subjects, 28

Table 1 Smoking, symptoms, and atopy

\begin{tabular}{llccccc}
\hline & Total & Current smokers & Ex-smokers & Non-smokers & Atopic & Non-atopic \\
\hline WRRS & 21 & 7 & 4 & 10 & 13 & 8 \\
WRNS & 15 & 5 & 3 & 7 & 10 & 5 \\
No symptoms & 77 & 31 & 15 & 31 & 25 & 52 \\
\hline
\end{tabular}

WRRS - respiratory symptoms related to grain dust; WRNS — nasal symptoms related to grain dust.

Table 2 Skinprick test responses to mites in farmworkers

\begin{tabular}{|c|c|c|c|c|c|}
\hline & $\begin{array}{l}\text { No of positive } \\
\text { SPT responses }\end{array}$ & $\begin{array}{l}\text { Geometric mean weal } \\
\text { area }\left(\mathrm{mm}^{2}\right)\end{array}$ & $\begin{array}{l}\text { Correlation coefficient } \\
v D P\end{array}$ & $\begin{array}{l}\text { Correl } \\
\text { SPTv } \\
(\%)\end{array}$ & $\begin{array}{l}\text { ation coefficient } \\
R A S T \text { and concordance }\end{array}$ \\
\hline $\begin{array}{l}\text { Glycyphagus destructor } \\
\text { Glycyphagus domesticus } \\
\text { Tyrophagus putrescentiae } \\
\text { Acarus farris } \\
\text { Acarus siro } \\
\text { Dermatophagoides pteronyssinus }\end{array}$ & $\begin{array}{l}28 \\
25 \\
22 \\
24 \\
25 \\
28\end{array}$ & $\begin{array}{c}8 \cdot 92 \\
8 \cdot 62 \\
8 \cdot 39 \\
7 \cdot 38 \\
8 \cdot 24 \\
10 \cdot 0\end{array}$ & $\begin{array}{l}0.931 \\
0.869 \\
0.794 \\
0.81 \\
0.884 \\
1\end{array}$ & $\begin{array}{l}0 \cdot 573 \\
0 \cdot 536 \\
0 \cdot 47 \\
0 \cdot 457 \\
0 \cdot 391 \\
0 \cdot 634\end{array}$ & $\begin{array}{l}81 \% \\
78 \% \\
81 \% \\
71 \% \\
71 \% \\
84 \%\end{array}$ \\
\hline
\end{tabular}

SPT-skinprick test; DP-Dermatophagoides pteronyssinus. 


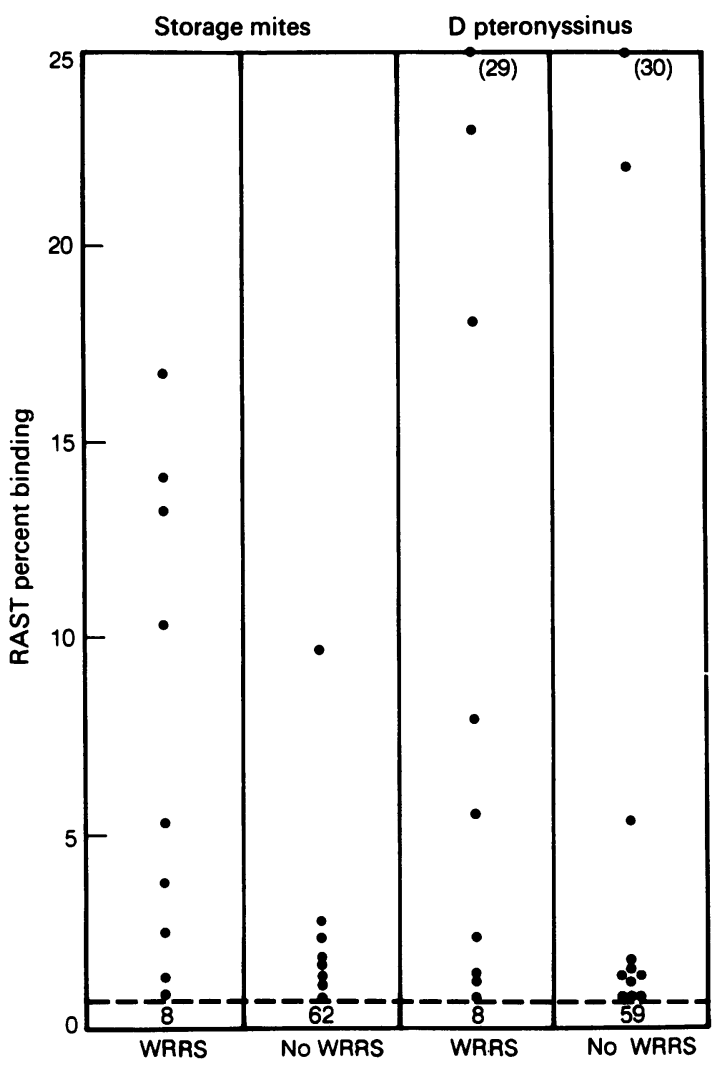

Fig 1 RAST binding to mixed storage mites and Dermatophagoides pteronyssinus in farmworkers in relation to work related respiratory symptoms (WRRS).

had a positive skin test response to $D$ pteronyssinus and 23 to grass pollen. Thirty farmworkers had a positive skin test response to one or more storage mite. Nine of the atopic subjects had a negative response to D pteronyssinus.

The skin test results are shown in table 2. Positive skin test responses to the different species of storage mite occurred with equal frequency. The rank correlation coefficients for the 99 subjects between skinprick test weal areas for storage mite and for $D$ pteronyssinus were significant for all species of storage mite (column 3, table 2).

\section{SPECIFIC IgE TO STORAGE MITES, D PTERO-} NYSSINUS, AND WHEATGERM MEDIUM

Seventeen subjects had $D$ pteronyssinus specific IgE and 18 had storage mite specific IgE. Radioallergosorbent serum titre (RAST) binding is shown in relation to occupational respiratory symptoms in figure 1 . In the 85 subjects whose serum was tested for specific IgE there was a significant correlation between levels of specific IgE and skinprick weal areas for all storage
Table 3 Skinprick test responses to storage mites (SM) and Dermatophagoides pteronyssinus $(D P)$ in relation to respiratory symptoms related to grain dust

\begin{tabular}{|c|c|c|}
\hline & $\begin{array}{l}\text { No (\%) with } \\
\text { positive response } \\
\text { to DP }\end{array}$ & $\begin{array}{l}\text { No (\%) with } \\
\text { positive response } \\
\text { to SM }\end{array}$ \\
\hline \multirow{2}{*}{$\begin{array}{l}\text { Total group }(n=99) \\
\text { WRRS }(n=21) \\
\text { WRNS }(n=15) \\
\text { No WRNS or WRRS } \\
(n=77)\end{array}$} & $\begin{array}{r}28(28.2 \%) \\
11(52.4 \%) \\
8(53.3 \%)\end{array}$ & $\begin{array}{r}30(30 \cdot 3 \%) \\
11(52 \cdot 4 \%) \\
7(46 \cdot 6 \%)\end{array}$ \\
\hline & $17(22 \cdot 1 \%)$ & $19(24 \cdot 7 \%)$ \\
\hline
\end{tabular}

WRRS - respiratory symptoms related to grain dust; WRNS - nasalA symptoms related to grain dust.

mite species $(\mathrm{r}=0.39-0.57, \mathrm{p}<0.001)$. Skinprick test responses to $D$ pteronyssinus were also correlated $P$ significantly with specific IgE $(r=0.634, \mathrm{p}<0.001)_{\infty}$

IgE specific for wheatgerm mite growth medium was measured in the serum of 25 subjects who had IgED specific for storage mite mix, 10 of whom had work $\frac{3}{0}$ related respiratory or nasal symptoms and 15 of whom did not. Wheatgerm specific IgE was not associatect with work related symptoms, being found in five of the 10 subjects with symptoms and in seven of the 15 with no symptoms $\left(\chi^{2}=0.06, p>0.9\right)$. IgE specific for storage mites and wheatgerm was measured in 10 s subjects with work related symptoms and eight of these showed over $1 \%$ RAST binding to storage mites whereas only two showed over $1 \%$ RAST binding to 0 wheatgerm.

There was a weak but significant correlation bet ween total IgE and IgE specific for storage mite mix.

\section{RELATION BETWEEN SYMPTOMS AND}

IMMUNOLOGICAL FINDINGS

Of the 23 farmworkers with nasal or respiratoryx symptoms after grain exposure, $52 \%$ had a positive skin test response to one or more storage mites and $48 \%$ a positive response to $D$ pteronyssinus. Of those without such symptoms, $25 \%$ had a positive skin test response to storage mites and $22 \%$ a positive response-

Table 4 Storage mite (SM) and Dermatophagoides pteronyssinus (DP) specific IgE in relation to respiratory symptoms related to grain dust

\begin{tabular}{|c|c|c|}
\hline & $\begin{array}{l}\text { No (\%) with } \\
\text { positive } R A S T \\
\text { response to } D P\end{array}$ & $\begin{array}{l}\text { No (\%) with } \\
\text { positive RAST } \\
\text { response to SM }\end{array}$ \\
\hline $\begin{array}{l}\text { Total group }(\mathbf{n}=\mathbf{8 5}) \\
\text { WRRS }(\mathbf{n}=17) \\
\text { WRNS }(\mathbf{n}=10) \\
\text { No WRRS or WRNS }\end{array}$ & $\begin{array}{l}17(20 \%) \\
9(52 \cdot 9 \%) \\
6(60 \%)\end{array}$ & $\begin{array}{c}18(21 \cdot 2 \%) \\
10(58 \cdot 8 \%) \\
6(60 \%)\end{array}$ \\
\hline$(n=65)$ & $8(12 \cdot 3 \%)$ & $6(9 \cdot 2 \%)$ \\
\hline
\end{tabular}

WRRS - respiratory symptoms related to grain dust; WRNS-nasab symptoms related to grain dust. 


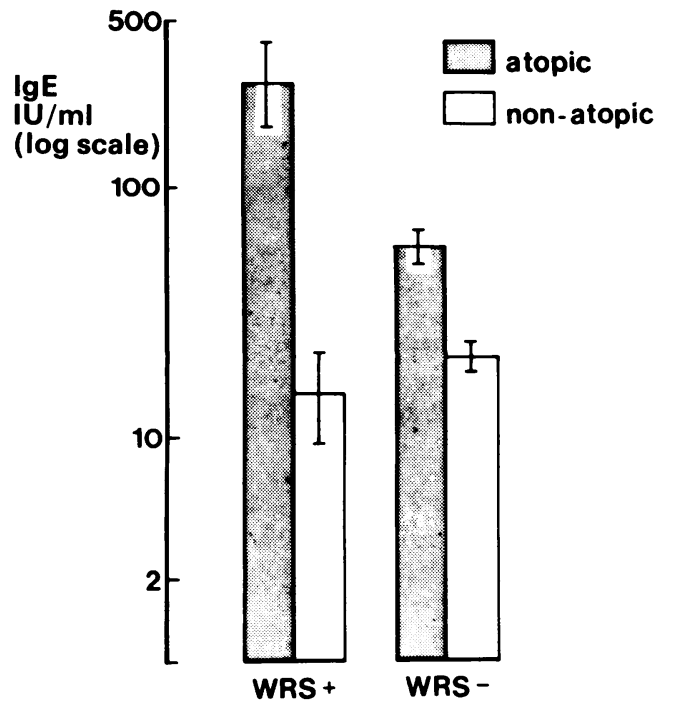

Fig 2 Total IgE levels in relation to atopy and work related symptoms (WRS) in farmworkers.

to $D$ pteronyssinus $\left(\chi^{2}=4.89\right.$ for storage mites, $6 \cdot 18$ for $D$ pteronyssinus; $p<0.05$ ) (tables 3 and 4 ).

Neither respiratory nor nasal work related symptoms were associated with a positive skin test response to grass pollen $\left(\chi^{2}=1 \cdot 79, \mathrm{p}>0 \cdot 1\right)$, RAST binding to wheatgerm medium $\left(\chi^{2}=0.06, \mathrm{p}>0.9\right)$, or current cigarette smoking $\left(\chi^{2}=0 \cdot 168, \mathrm{p}>0 \cdot 5\right)$. Total IgE was significantly higher in atopic subjects with work related symptoms than in atopic subjects without such symptoms. The differences in total IgE between nonatopic subjects with and without work related symptoms were not, however, significant (fig 2).

\section{MITE CONTENT OF STORED GRAIN}

The mite content of grain samples from 16 farms is shown in table 5. The moisture content was always over $15 \%$. All samples contained some storage mites; no $D$ pteronyssinus were found in any.

Table 5 Mite content of grain samples from 16 farms

\begin{tabular}{|c|c|c|c|c|}
\hline Grain & Site & $\begin{array}{l}\text { No of } \\
\text { samples }\end{array}$ & $\begin{array}{l}\text { Average } \\
\text { moisture } \\
\text { content }(\%)\end{array}$ & $\begin{array}{c}\text { Mites } \\
\text { found }\end{array}$ \\
\hline Wheat & $\begin{array}{l}\text { Bins, } \\
\text { floor }\end{array}$ & 18 & 15.9 & \multirow{5}{*}{$\begin{array}{l}\text { GDs,AS,TL, } \\
\text { TP,AF,Ch } \\
\text { GDs,AS,TP } \\
\text { TL,Ch } \\
\text { GDs,Ch } \\
\text { GDs,TP,TL, } \\
\text { Ch } \\
\text { GDs,AS,TL, } \\
\text { AF,GDm,Ch }\end{array}$} \\
\hline Barley & $\begin{array}{l}\text { Bins, } \\
\text { floor }\end{array}$ & 11 & $15 \cdot 6$ & \\
\hline Oats & Bins & 2 & - & \\
\hline Straw & Bales & 7 & - & \\
\hline Hay & Bales & 6 & - & \\
\hline
\end{tabular}

GDs-Glycyphagus destructor; TP-Tyrophagus putrescentiae; $\mathrm{AF}-$ Acarus farris; $\mathrm{Ch}-$ Cheyletus spp; $\mathrm{GDm}-$ Glycyphagus domesticus; AS-Acarus siro; TL-Tyrophagus longior.
Discussion

There was a significant association between respiratory symptoms after grain dust exposure and storage mite specific IgE in the 101 Essex farmworkers who took part in this study. All the farmworkers had been exposed to stored grain, and the grain that they handled contained storage mites. The storage mites may therefore be responsible for symptoms described by these farmworkers after exposure to stored grain.

Storage mite allergy has also been documented in Finnish, ${ }^{13}$ Swedish, ${ }^{5}$ and Canadian ${ }^{14}$ farmworkers exposed to grain, and also in Scottish farmworkers whose hay may become contaminated with storage mites. ${ }^{4}$ Previous studies of respiratory symptoms in farmworkers in Britain have been concerned with farmer's lung ${ }^{1516}$ or with symptoms occurring during the grain harvest. ${ }^{2}$ The prevalence of farmer's lung is known to be low in East Anglia ${ }^{16}$ and only one subject in the present survey reported a history of farmer's lung.

The association between work related symptoms and positive skin test responses and storage mite specific IgE could possibly be explained by a common association of the two with a third environmental factor. Previous reports have suggested that either grain dust itself or moulds contaminating grain may cause allergic symptoms in farmworkers. The present survey does not exclude the possibility that mould spores might have contributed to symptoms in these farmworkers. There was no relation, however, in this study between work related symptoms and positive skin test responses to Aspergillus fumigatus. A comprehensive evaluation of the role of mould spores in the pathogenesis of respiratory symptoms in these farmworkers would require a detailed environmental survey of each farm, which was beyond the resources of this study. Our study provides no evidence that grain itself was responsible for symptoms in these farmworkers. There was no association between wheatgerm specific IgE and work related symptoms and RAST binding was stronger for storage mites than for wheatgerm in subjects who had symptoms.

An allergic response to storage mites has not been found in other workers handling stored grain. Several surveys of grain elevator workers in the United States and Canada have found a high prevalence of respiratory symptoms in grain workers and an association between symptoms and cigarette smoking, ${ }^{67}$ but no increased prevalence of atopy or positive skin test responses to storage mites.

The differences between the results of the present study and the North American studies may reflect differences in the contaminants of English and American grain. The moisture content found in the grain stored on the farms that we surveyed was always greater than $15 \%$ whereas North American grain is 
likely to be considerably drier, and this will discourage the growth of storage mites. ${ }^{17}$ Indeed, storage mite allergy has not been found in any of the American surveys that have looked for it.

In the present study a positive skin test response or RAST binding to $D$ pteronyssinus was associated with symptoms due to grain dust exposure, even though no D pteronyssinus were found in the stored grain. This may result from some allergen cross reactivity between D pteronyssinus and storage mites, though the extent to which this might occur is unknown. Significant correlations between storage mites and $D$ pteronyssinus for both skin test weal areas and RAST binding have been found in epidemiological surveys (including the present study) but limited immunological studies have not so far shown extensive cross allergenicity. ${ }^{18} 19$ An alternative explanation for the relation between $D$ pteronyssinus and work related symptoms could be that the atopic state predisposes to the development of storage mite specific IgE, and therefore to symptoms developing on exposure to stored grain. The present study cannot distinguish between these possibilities.

Total IgE levels were greater in atopic farmworkers with work related symptoms than in atopic farmworkers without symptoms or in symptomless atopic and non-atopic farmworkers. There was also a weak but significant correlation between IgE specific for storage mites and $D$ pteronyssinus and total IgE. The association between symptoms and skin test responses and IgE specific for both $D$ pteronyssinus and storage mites may therefore result from non-specific binding in subjects with a high total IgE level. This is unlikely because of the weakness of the correlation between total and specific IgE.

Our results suggest that storage mite allergy is responsible for some at least of the work related respiratory and nasal symptoms in East Anglian farmworkers handling stored grain. Grain itself or mould spores contaminating grain could be responsible for symptoms in some individuals; but the lack of relation between work related symptoms and wheatgerm specific IgE suggests that grain is unlikely to be a major allergen, and the lack of symptoms during the harvest in these workers argues against a major role for mould spores. Our findings suggest that attempts to reduce the storage mite population in stored grain may reduce the prevalence of respiratory symptoms in workers exposed to grain grown in the United Kingdom.

We are grateful to the Pest Infestation Control Laboratory, Cambridge, for mite counts, and to the Pest Infestation Control Laboratory, Slough, for the generous supplies of mites. We also thank Caroline Gould for help with skinprick testing, Laura Roberts for typing the manuscript, and the farmers and farmworkers of Essex for agreeing to participate in the study. The study would not have been possible without the assistance of Dr M J S Coe, of the Employment $\stackrel{\bar{F}}{\stackrel{9}{9}}$ Medical Advisory Service. A D B was supported by a음 grant from the Chest, Heart, and Stroke Association. $\frac{\bar{\sigma}}{\overline{0}}$

\section{References}

1 Lunn JA, Hughes DTD. Pulmonary hypersensitivity to ڤ the grain weevil. Br J Ind Med 1967;24:158-61.

2 Darke CS, Knowelden J, Lacey J, Milford Ward A. Respiratory disease of workers handling grain. Thorax $\vec{\omega}$ 1976;31:294-302.

3 Warren P, Cherniak RM, Tse KS. Hypersensitivity $\overrightarrow{\vec{x}}$ reactions to grain dust. $J$ Allergy Clin Immunol $\vec{\omega}$ 1974;54:139-49.

4 Cuthbert OD, Brostoff J, Wraith DG, Brighton WG. "Barn Allergy": asthma and rhinitis due to storage mites. Clin Allergy 1979;9:229-36.

5 van Hage-Hansten M, Johansson SGO, Hoglund S, Tull $\stackrel{\circ}{\supset}$ $P$, Wiren A, Zetterstrom $O$. Storage mite allergy is $\vec{c}$ common in a farming population. Clin Allergy $\mathbb{D}$ 1985; 15:555-64.

6 Broder I, Mintz S, Hutcheon M, et al. Comparison of $\frac{\mathbb{D}}{3}$ respiratory variables in grain elevator workers and civic outside workers of Thunder Bay, Canada. Am Rev $\stackrel{\text { D }}{\text { - }}$ Respir Dis 1979;119:193-203.

7 doPico GA, Reddan W, Tsiatis A, Peters ME, Rankin J. Epidemiologic study of clinical and physiologic parameters in grain handlers of northern United States. Am Rev Respir Dis 1984;130:759-65.

8 Dosman JA, Cotton DJ, Graham BL, Li KYR, Froh F, Barnett DG. Chronic bronchitis and decreased forced

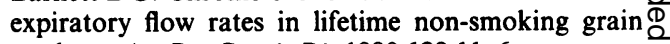
workers. Am Rev Respir Dis 1980;120:11-6.

9 Blainey AD. MD thesis, University of Cambridge, 1987. 윽

10 Pepys J. Atopy. In: Gell PGH, Coombs RRA, eds. Clinical aspects of immunology. Oxford: Blackwell, 1975.

11 Ceska E, Eriksson R, Varga JM. Radioimmunosorbent assay of allergens. J Allergy Clin Immunol 1972;49:1-9. 음

12 Armitage P. Statistical methods in medical research. $\stackrel{\sim}{\times}$ Oxford: Blackwell, 1971.

13 Terho EO, Husman K, Vohlonen I, Rautalahti M, Takainen M. Allergy to storage mites or cow dander as $\bigcirc$ a cause of rhinitis among Finnish dairy farmers. Allergy 1985;40:23-6.

14 Warren CPW, Holford-Stevens V, Sinha RN. Sensi-글 tisation in a grain handler to the storage mite Lepidoglyphus destructor (Schrank). Ann Allergy․ㅡㄹ. 1983;50:30-3.

15 Hapke EJ, Seal RME, Thomas GO. Farmer's lung. of Thorax 1968;23:451-68.

16 Grant IWB, Blyth W, Wardrop VE, Gordon RM, N Pearson JCG, Mair A. Prevalence of farmer's lung in Scotland: a pilot survey. Br Med J 1972;i:530-4.

17 Service MW. A guide to medical entomology. London: Macmillan, 1980.

18 Agha M, Gnanasakthy. A cluster analysis of the effects of $\stackrel{\infty}{+}^{+}$ storage mite as allergens in relation to certain occupations and living conditions. Clin Allergy $\frac{\vec{\Phi}}{\mathbb{D}}$ 1980;11:499-504.

19 Arlian LG, Geis DP, Vyszenski-Mayer DL, Bernstein IL, $\overrightarrow{\mathbb{Q}}$ Gallagher JS. Antigenic and allergenic properties of the ${ }_{\sigma}$ storage mite Tyrophagus putrescentiae. J Allergy Clin Immunol 1984;74:166-71. 